\title{
Pedagogia hospitalar: intervenções na unidade pediátrica a partir da contação de histórias
}

\section{Hospital pedagogy: interventions in the pediatric unit from history accounting}

\author{
Maria Fatima Belancieri ${ }^{1}$, Kátia Regiane Rodrigues ${ }^{2}$, Vera Lucia Messias Fialho \\ Capellini ${ }^{3}$, Verônica Lima dos Reis ${ }^{4}$
}

\section{Resumo}

\begin{abstract}
A criança ao ser hospitalizada por longo período de tempo perde o contato com o seu cotidiano, deixando de ir à escola, de brincar, o que poderá afetar suas condições psicoemocionais e sociais. Visando amenizar tais repercussões, diversas atividades lúdicas podem ser desenvolvidas durante o período de hospitalização, como a contação de histórias, por exemplo. Assim, este estudo teve como objetivo estruturar e avaliar o desenvolvimento de uma proposta de intervenção a partir da Contação de Histórias para pacientes pediátricos hospitalizados. O estudo foi realizado na brinquedoteca de um hospital do interior paulista, a partir de 10 encontros, com duração de 40 a 60 minutos, utilizando-se diversos recursos lúdicos e histórias infantis. Participaram do estudo 50 crianças de ambos os sexos, com idades entre 1 e 13 anos. Os resultados apontaram que a Pedagogia Hospitalar e, especificamente, a Contação de Histórias pode trazer contribuições à instituição hospitalar e as crianças internadas, facilitando o enfrentamento do processo cirúrgico e hospitalização, bem como pode promover uma aproximação com o cotidiano escolar e a aprendizagem.
\end{abstract}

Palavras-chave: Pedagogia hospitalar. Contação de histórias. Classe hospitalar.

\begin{abstract}
The child being hospitalized for a long period of time loses contact with their daily life, leaving school, playing, which may affect their psycho-emotional and social conditions. In order to alleviate such repercussions, several play activities can be developed during the hospitalization period, such as storytelling, for example. The purpose of this study was to structure and evaluate the development of an intervention proposal from the Storytelling for hospitalized pediatric patients. The study was carried out in the toy library of a Hospital in the interior of São Paulo, from 10 meetings, lasting 40 to 60 minutes, using a variety of playful resources and children's stories. Fifty children of both sexes, aged between 1 and 13 years, participated in the study. The results pointed out that Hospital Pedagogy and, specifically, storytelling can bring contributions to the hospital and hospitalized children, facilitating the coping of the surgical process and hospitalization, as well as promoting an approximation with daily school life and learning.
\end{abstract}

Keywords: Hospital pedagogy. Storytelling. Hospital class.

\footnotetext{
1 Doutora em Psicologia pela Pontifícia Universidade Católica de São Paulo. Professora do Centro Universitário de Adamantina. E-mail: mfbelancieri@fai.com.br

2 Especialista em Educação Especial pela Universidade Paulista “Júlio de Mesquita Filho" Bauru/SP

3 Doutora em Educação Especial pela Universidade Federal de São Carlos. Docente da Pós-Graduação Stricto Senso (Mestrado e Doutorado), Universidade Estadual "Julio de Mesquita Filho" - Bauru/SP.

4 Doutora em Educação Escolar. Pesquisadora voluntária, Universidade Estadual "Julio de Mesquita Filho" - Bauru/SP
} 


\section{Introdução}

O campo de atuação do pedagogo tem se ampliado para outros espaços que não apenas no ambiente escolar, sobretudo, a partir das Diretrizes Curriculares do Curso de Pedagogia de 2006 (BRASIL, 2006). Empresas, igrejas, instituições e hospitais também podem contar, atualmente, com as ações educativas desse profissional, visando à escolarização e a formação humana. A atuação em hospitais, área denominada Pedagogia Hospitalar, é um exemplo desta nova função do pedagogo.

A Pedagogia Hospitalar visa garantir a escolarização a estudantes em idade escolar, envolvidos por situações que os afastem da escola, como enfermidades temporárias ou permanentes e hospitalização, contribuindo para a criação de um ambiente de aprendizagem sistematizado e humanizado. Este atendimento pedagógico à criança enferma ou hospitalizada é previsto no artigo 13 da Resolução n ${ }^{\circ}$ 02/2001 do Conselho Nacional de Educação (BRASIL, 2001) e nas orientações para classe hospitalar e atendimento domiciliar do Ministério da Educação-MEC (BRASIL, 2002).

De acordo com Matos (2009) há considerável melhora na evolução clínica de pacientes envolvidos em atividades pedagógicas, visto que estas podem reaproximar o aluno/paciente do convívio com atividades de sua rotina, por exemplo, das atividades escolares. Ressalta ainda que as relações e ações pedagógicas durante a hospitalização da criança são extremamente importantes, o que contribui positivamente para o enfrentamento da doença e favorece o desenvolvimento social, cognitivo e físico

Assim, levando-se em consideração as contribuições da Pedagogia Hospitalar, este estudo teve como objetivo estruturar e avaliar o desenvolvimento de uma proposta de intervenção a partir da Contação de Histórias para pacientes pediátricos hospitalizados.

\section{A Presença da Pedagogia no Contexto Hospitalar e a Classe Hospitalar}

A presença do pedagogo no contexto hospitalar remonta à década de 1950, quando foi criada a primeira Classe Hospitalar, vinculada ao Hospital Municipal Menino Jesus, no Rio de Janeiro, que visava ao atendimento pedagógico a estudantes hospitalizados, além de promover um espaço mais agradável e prazeroso, mais próximo de seu ambiente escolar (ESTEVES, 2008).

Ressalta-se que o reconhecimento deste tipo de atendimento ocorreu a partir da Resolução $n^{\circ}$ 41/1995, que estabelece o Estatuto da Criança e do Adolescente Hospitalizado, em que a criança tem o "Direito de desfrutar de alguma forma de recreação, programas de educação para a saúde e acompanhamento do currículo escolar durante sua permanência hospitalar" (CONSELHO NACIONAL DOS DIREITOS DA CRIANÇA E DO ADOLESCENTE, 1995).

A legislação que ampara a atuação em Pedagogia Hospitalar é composta pela Lei Estadual $n^{\circ} 10.685 / 2000$ (SÃO PAULO, 2000), que dispõe sobre o acompanhamento educacional da criança e do adolescente internados e a Resolução CNE/CEB $n^{\circ} 02 / 2001$, que institui as Diretrizes Nacionais para a Educação Especial na Educação Básica (BRASIL, 2001).

A Secretaria da Educação Especial (BRASIL, 2002) aborda a adequação do professor no ambiente Hospitalar como forma de integrá-lo ao ambiente e de fornecer esclarecimentos em como este administrará sua prática.

Mesmo diante das políticas públicas para o ingresso educacional dos estudantes hospitalizados, muitas instituições não reservam espaço físico adequado, sendo necessário, dessa forma, diálogos visando esclarecer a direção hospitalar os benefícios de tal serviço.

Como mencionado por Castro (2009), o estudante quando necessita ficar hospitalizado por longo período de tempo, perde o contato com o seu 
cotidiano, com o habitual, deixa de ir à escola, de brincar com seus pares como fazia anteriormente. Muitas vezes, no quadro das diferentes patologias, a criança fica debilitada, o que afeta suas condições psicoemocionais e sociais. O desconforto físico, por si mesmo, gera sentimentos de angústia, incertezas e medos. As condições de isolamento e restrições que a hospitalização submete, contribuem para que seu estado emocional se agrave numa das fases mais curtas e importantes, quanto ao desenvolvimento humano, que é a infância.

É importante esclarecer a necessidade de uma articulação entre o professor da escola de origem do educando, com o professor Coordenador e Administrador do Projeto Pedagógico Hospitalar, e que, a partir das informações obtidas, passe a conhecer o processo/currículo educacional ao qual o aluno estava integrado, visando práticas mais efetivas, bem como, a descaracterizar as atividades administradas apenas como momentos de ludicidade ou práticas vazias de conteúdos significativos, uma vez que, esta intervenção tem por finalidade, posteriormente, reinserir a criança no ambiente escolar sem que seu retorno lhe cause prejuízos quanto ao processo de ensino e aprendizagem.

$\mathrm{O}$ espaço no qual as atividades pedagógicas ocorrerão, deve ser pensado de forma a estabelecer um ambiente favorável à aprendizagem. É importante que haja uma sala organizada com estruturas que reproduzam o ambiente escolar. Isso é possível, atualmente, graças à Lei n ${ }^{\circ} 11.104 / 2005$, que regulamenta a necessidade de brinquedotecas em Instituições Hospitalares (BRASIL, 2005).

Considerando que antes a criança se via num outro contexto, e que agora se sente frágil diante das circunstâncias de afastamento do convívio afetivo familiar, social e escolar, é importante pensar num ambiente psicológico e pedagogicamente agradável para ela.

Alunos inseridos no contexto pedagógico de ambientes hospitalares, respondem de forma mais significativa em sua recuperação física.
"Os profissionais de saúde envolvidos no processo de cuidado/tratamento do paciente/aluno relatam que a criança que recebe algum tipo de atenção educacional durante o internamento tende a ser mais receptiva calma e realiza as tarefas terapêuticas com disposição, o que auxilia em sua recuperação" (CASTRO, 2009, p. 43).

Os profissionais que optarem pelo exercício da Pedagogia Hospitalar, além de pedagogos especializados, uma vez que esta nasce na Educação Especial, deverão, ainda, capacitar-se psicologicamente para o enfrentamento de situações do trabalho com alunos que, muitas vezes, estarão acometidos por doenças graves ou fora de recursos terapêuticos.

A criança está no período de formação de sua identidade, e para tal, deverá ser estimulada para um pleno desenvolvimento de sua personalidade. Assim, pensar em ações em parceria com a equipe multidisciplinar para os internos é de suma importância.

"O educador, o assistente social, o psicólogo e os demais profissionais afins, devem buscar em si próprios o verdadeiro sentido de "educar", devem ser o exemplo vivo dos seus ensinamentos e converter suas profissões numa atividade cooperadora e do engrandecimento da vida" (MATOS; MUGIATTI, 2006, p. 26).

Desta forma, deverão ser oferecidas a esses educandos, atividades pedagógicas que se interrelacionem com o contexto escolar de cada uma, e colaborar para aqueles que ali permanecerem, condições de aprendizagens significativas.

É observado que a criança hospitalizada sentese valorizada quando entra em contato com as práticas pedagógicas e, ainda mais, quando encontra um espaço de repensar o seu convívio social. Sentimentos de bem estar, autoestima, maior suportabilidade dentre outros, são revelados quando estudantes hospitalizados são confrontadas com as práticas hospitalares (CASTRO, 2009). A escolarização durante a hospitalização garante não 
só a continuidade do processo de educação formal como também promove o bem estar e qualidade de vida à criança.

Assim, o trabalho em instituições hospitalares, evidencia uma prática que contribui para que a criança possa compreender o período de internação, a promoção de atividades que a remetam ao ambiente de aprendizagem e a tentativa de favorecer momentos de socialização e ludicidade.

\section{A Importância da Contação de Histórias nas Práticas Educativas}

Meirelles (1997) revela que a arte de contar histórias é propagada desde os primórdios da civilização e por meio dela se perpetua a literatura oral, comunicando de indivíduo a indivíduo e de povos para povos o que os homens têm selecionado da sua experiência como indispensável à vida.

Nas escolas, essa atividade emerge como um fator em potencial para o progresso da capacidade criativa dos estudantes. Por meio das histórias contadas em livros, a criança fica livre para imaginar cenas das mais variadas formas. Nesse sentido, inúmeras são as possibilidades para o uso da contação de histórias na sala de aula. Além da diversão, atua no desenvolvimento da inteligência, criatividade e socialização da criança, sendo ainda um estímulo ao prazer da leitura. (VILLARDI, 1997). Complementando, Sisto (2001), ressalta ainda que favorece a oralidade o aprendizado e a formação da personalidade da criança. Mas, é fundamental que o professor contador, busque condições para chamar a atenção para a história contada, utilizando-se de estratégias e recursos apropriados ao se dedicar a tal atividade.

Por meio dos contos, o leitor ou ouvinte poderá, ainda, superar seus conflitos internos:

O conto de fadas é em grande parte o resultado de um conteúdo comum consciente, não de uma pessoa em particular, mas pelo consenso de várias a respeito daquilo que consideram problemas universais e do que aceitam como soluções desejáveis. Se todos esses elementos não estivessem presentes num conto de fadas, ele não seria recontado por gerações e gerações. Um conto só era recontado repetidamente, e ouvido com grande interesse, se satisfizesse as exigências conscientes e inconscientes de muitas pessoas (BETTELHEIM, 2008, p. 52).

Alguns pressupostos são fundamentais na arte de contar histórias e, dentre eles, estão a interação, o conhecimento da história, a entonação de voz, as expressões faciais e corporais que auxiliarão positivamente nesta arte. A história traz vida e imagem ao pensamento, permite que a criança dê vida aos personagens e as cenas.

Para o início da Contação de Histórias é preciso tomar algumas medidas para propiciar favoravelmente o momento, dessa forma, é necessário preparar o ambiente, tanto físico, quanto estimular as percepções emocionais dos estudantes.

É importante ao contador, não ter pressa, explorar cada palavra, cada frase, ter prazer nas palavras, tornando o ambiente agradável, onde os ouvintes sintam-se no verdadeiro cenário da história.

$\mathrm{O}$ ato de contar histórias dá condições ao ouvinte de criação individual, numa sociedade tão reprodutora, que apresenta tudo pronto, Bettelheim (2008, p. 11) ressalta que:

Para que uma história realmente prenda atenção da criança, deve entretê-la e despertar a sua curiosidade. Contudo, para enriquecer a sua vida, deve estimular-lhe a imaginação: ajudá-la a desenvolver seu intelecto e a tornar claras suas emoções; estar em harmonia com suas ansiedades e aspirações; reconhecer plenamente suas dificuldades e, ao mesmo tempo, sugerir soluções para os problemas que a perturbam.

Assim, a partir das reflexões sobre este tema, buscou-se a partir de uma ação educativa responder 
aos seguintes questionamentos: como acontecem as relações pedagógicas no ambiente hospitalar quando estudantes são expostos às intervenções educativas sistematizadas por meio da Contação de Histórias? Que respostas são emitidas pelos estudantes hospitalizados diante da intervenção? O que os pais pensam sobre essa prática no contexto hospitalar?

A expectativa é que a Prática Pedagógica sirva como um fator de estímulo à criança hospitalizada e torne seu momento na Instituição como uma vivência humanizada, além de ser aplicada com intencionalidade pedagógica.

\section{Metodologia}

Caracterizado como uma pesquisa de natureza interventiva, este estudo foi realizado com crianças hospitalizadas na pediatria de um Hospital Estadual do interior paulista para procedimentos eletivos de dois ou três dias.

A estruturação da proposta de intervenção ocorreu da seguinte forma: após aprovação do projeto de pesquisa pelo Comitê de Ética na Plataforma Brasil (parecer no 1.818.229) e do Núcleo de Estudos e Pesquisas do Hospital Estadual, foi realizado contato com a coordenadora do setor de Pediatria estabelecendo-se os dias e horários para a intervenção (Contação de Histórias), bem como o espaço físico.

As atividades de Contação de Histórias foram realizadas na brinquedoteca da pediatria do hospital, as quartas e quintas-feiras, no período da tarde. A escolha destes dois dias ocorreu, especificamente, pelo fato de acontecerem as internações para procedimentos cirúrgicos, oportunizando uma ampla participação das crianças.

A brinquedoteca caracteriza-se como um espaço amplo, composto por uma sala e antessala, televisão, pufes, mesas, cadeiras e materiais lúdicos disponibilizados aos pacientes e familiares.
Foram realizados 10 encontros para Contação de Histórias, com duração de 40 a 60 minutos, utilizando-se como recursos fantoches, desenhos, livros de literatura infantil, gravador de áudio e câmera fotográfica.

No início das atividades, eram lançadas algumas questões aos participantes, visando um estabelecimento de vínculo e interação, bem como identificar alguns conhecimentos prévios, e, em seguida, solicitar auxílio no desenvolvimento da história.

Todos os encontros de Contação de Histórias foram registrados em diário de campo e gravados em áudio e imagem.

Ao final das intervenções, foi realizada uma entrevista semiestruturada com alguns pais das crianças hospitalizadas, visando identificar qual a compreensão deles sobre a contribuição da Contação de Histórias no processo de hospitalização, bem como no âmbito pedagógico.

Os dados coletados a partir da Contação de Histórias foram organizados de acordo com a técnica de análise de conteúdo de Bardin (2009) e analisados qualitativamente. Assim, após a leitura dos dados contidos no diário de campo, buscou-se agrupar e categorizá-los, buscando-se pontos chaves que esclarecessem nossos objetivos. Dessa forma, foram criadas três grandes categorias: Emoções e sentimentos diante do momento vivenciado; Aspectos relacionados à escola e aprendizagem e Importância da proposta para os pais ou responsáveis.

\section{Resultados e Discussão}

Como resultados, foi possível observar que o hospital alvo da proposta interventiva, apresenta uma grande rotatividade de pacientes no setor pediátrico. Desta forma, participaram deste estudo 50 crianças de ambos os sexos, com idades variando de 1 a 13 anos. 
Antecedendo aos encontros de Contação de Histórias, a enfermeira responsável pelo setor de Pediatria realizava a orientação sobre quais pacientes poderiam participar. Posteriormente, procedia-se à visita aos pacientes, em que a contadora de história se apresentava, fazendo o convite à criança e aos pais ou acompanhantes para participarem. No quadro abaixo, pode-se visualizar as histórias contadas em cada sessão com os respectivos números de participantes.

Quadro 1 - Número de encontros, participantes e histórias contadas

\begin{tabular}{|c|c|c|}
\hline Encontro & História/atividades & Participantes \\
\hline 1 & Branca de neve e os sete anões & 4 \\
\hline 2 & Festa no céu & 11 \\
\hline 3 & Chapeuzinho amarelo & 5 \\
\hline 4 & Chapeuzinho vermelho & 3 \\
\hline 5 & Os três porquinhos & 3 \\
\hline 6 & Chapeuzinho vermelho & 7 (5 pais) \\
\hline 7 & Os três porquinhos & 5 \\
\hline 8 & Branca de neve e os sete anões & 2 \\
\hline
\end{tabular}

Fonte: Dados da pesquisa.

As atividades eram iniciadas com algumas questões, visando ao estabelecimento de um vínculo de confiança, buscando-se uma interação ativa com as crianças, bem como, para saber sobre conhecimentos prévios das histórias. Quando já conheciam a história, as crianças auxiliavam na contação, a partir da manipulação dos fantoches, dos livros infantis ou de qualquer outro material apresentado, recontando, por vezes, partes da história.

As histórias contadas foram repetidas em alguns encontros, em razão da rotatividade dos pacientes. Assim, a história da Branca de neve e os sete anões foi contada no primeiro e oitavo encontro, sendo escolhido um trecho pontual da história, em que a Branca de Neve se vê em um lugar desconhecido, a floresta, o que a faz sentir-se perdida, porém, ao encontrar a casa dos sete anões sente-se mais segura, principalmente, após a amizade que se desenvolve entre eles. Nesse sentido, tomou-se a "amizade" como objetivo principal a ser desenvolvido, além de promover o envolvimento com o lúdico, a socialização e o ambiente escolar. Buscou-se aqui, estabelecer uma relação entre o ambiente da história e o contexto hospitalar, ambos, desconhecidos, em que a equipe hospitalar e os novos amigos, assim como os anões, poderão ajudá-la neste momento de possível medo ou angústia diante da hospitalização.

Castro et al. (2010) ressalta o valor terapêutico da contação de história, promovendo uma redução dos impactos negativos do isolamento do contexto familiar e escolar, contribuindo para o bem-estar e a qualidade de vida da criança durante o período de hospitalização.

No segundo e décimo encontro foi contada a história $A$ Festa no Céu, cujo objetivo foi demonstrar as diferenças entre os animais e as características de cada um, visando esclarecer às crianças suas particularidades e necessidades quanto ao seu estado físico e psíquico, podendo estas ser diferentes umas das outras, além de apontar a relação com as diferentes figuras existentes no hospital como os enfermeiros, médicos, psicólogos, entre outros, ressaltando que cada um deles tem sua particularidade nos cuidados à saúde. 
No terceiro encontro foi contada a história do Chapeuzinho Amarelo, uma reescritura do conto Chapeuzinho Vermelho, em que há uma reversão total das posições do lobo e do chapeuzinho, produzindo uma mudança de sentido do medo (BONOTO, 2003). Nesta história, uma garota tinha medo de muitas situações, porém, ao passo que as enfrentava, é remetida a um status de emancipação. Assim, após contar a história, procedeu-se a uma reflexão, visando desmistificar alguns medos provenientes do ambiente hospitalar e finalizando com a produção de um desenho sobre aspectos vivenciados durante a hospitalização que as crianças consideravam agradável.

Nos encontros quatro, seis e nove, foi contada a história do Chapeuzinho Vermelho, que teve como principal objetivo relacionar a figura do caçador com os enfermeiros, em que ao promover os cuidados às crianças hospitalizadas, desmistificam o medo dos procedimentos médicos, buscando um alívio e bem estar.

Para Bettelheim (2008), os contos de fadas auxiliam as crianças a buscar um significado para a vida, organizando seus pensamentos e sentimentos de forma a compreender a condição vivenciada. Assim, é importante que a criança aprenda que o medo é necessário, para que se reflita sobre o problema vivenciado e possa tomar os cuidados necessários para se proteger.

E por último, nos encontros cinco e sete, foi contada a história dos Três porquinhos, cujo objetivo foi promover a interação entre as crianças. Assim como os porquinhos que acabam unidos na mesma casinha, as crianças poderiam se apoiar mutuamente, unidos em um mesmo grupo, visando ao enfrentamento do adoecimento e hospitalização. Além disso, a proposta possibilitou também que, a partir das histórias contadas, as crianças pudessem produzir a sua própria história, com fatos ocorridos, seus desejos ou sobre seus medos.

A criança, de acordo com Vigotski (2003), apresenta uma capacidade criadora desde tenra idade. Assim, nas atividades lúdicas, cria novas formas e situações, a partir do imaginário. No conto de fadas, ativa sua imaginação e de forma mágica transforma o real, recriando a história a partir de suas percepções, possibilitando o enfrentamento de seus conflitos cotidianos.

No último encontro, a maioria dos pacientes estava em pós-operatório, ficando impossibilitados de se locomover até a brinquedoteca, além da indisposição para saírem de seus leitos. Dessa forma, a atividade foi realizada no leito, com dois pacientes apenas, em que um dos participantes procedeu à leitura da história. Esta os remeteu a seus animais de estimação, demonstrando a necessidade de falar sobre seu contexto familiar.

Ao final de cada encontro, as crianças perguntavam se haveria a Contação de Histórias no dia seguinte, demonstrando aceitação das atividades propostas. Observou-se que no decorrer das intervenções, as crianças passaram a interagir mais com outros participantes e foi possível observar alguns dados sobre as emoções e os sentimentos vivenciados, bem como o nível de aprendizagem dos participantes, conforme pode ser visualizado nas três categorias elencadas abaixo:

\section{1 - Emoções e sentimentos diante do momento vivenciado}

Durante os encontros para Contação de Histórias, foi possível observar algumas emoções e sentimentos relacionados ao momento vivenciado pelas crianças, como a insegurança, o medo e angústia diante da hospitalização e dos procedimentos médicos. Além da saudade dos entes familiares, necessidade de proteção e respostas para suas inquietações.

Algumas mudanças, também foram observadas no decorrer dos encontros, como o desenvolvimento da confiança e sentimentos de bem-estar quando expostos à leitura, além da alegria, generosidade e amor presentes nas histórias recriadas por eles, promovendo-se dessa forma maior envolvimento entre os participantes. 
No imaginário, as crianças conseguem expressar suas ideias e sentimentos, dialogar com os personagens, identificar semelhanças e diferenças entre elas e a história, criando novas possibilidades.

Numa casinha no meio do mato morava três menininhos que gostava de brincar no rio, mas um dia um precisou ir no médico. Ele ficou muito triste, mas depois passou, porque ele fez mais amiguinhos e no final ficou tudo bem, porque eles brincavam e contavam muitas historinhas legal.

Na recriação da história dos Três Porquinhos é possível observar que as crianças, buscam alivio para suas inquietações, alterando e reinterpretando e os personagens. Assis (2009) revela que neste momento de fragilidade, as crianças apresentam grande necessidade de serem ouvidas e compreendidas.

Nas situações representadas pelas crianças, aparecem questões relacionadas a valores universais como a liberdade, a verdade, a justiça, a amizade, a solidariedade, favorecendo uma compreensão sobre suas relações e convívio com a sociedade, que são confirmados por Souza e Bernardino (2011).

\section{2 -Aspectos relacionados à escola e aprendizagem}

Em relação à escolaridade e aprendizagem foi possível observar dificuldades na leitura e na escrita em, no mínimo, quatro dos participantes, que merecem passar por uma avaliação diagnóstica.

De maneira geral, observou-se uma boa interação das crianças com o material utilizado para a Contação de Histórias, bem como com seus pares, demonstrando interesse, entusiasmo e disposição na realização das atividades lúdicas desenvolvidas.

A partir de desenhos puderam representar o momento vivenciado, aprendendo a lidar com a situação do adoecimento e hospitalização. A familiarização com a história contada pode promover maior interação social e envolvimento por parte dos participantes, com a formação de pares no desenvolvimento das atividades.
Segundo Wallon (1975) uma das formas de expressão preferidas das crianças é o desenho, utilizado neste estudo, após a Contação de Histórias. Conforme o autor, por meio do desenho, a criança pode revelar seus pensamentos, os conhecimentos conceituais que tem da realidade e dos aspetos mais significativos de sua experiência. Neste sentido, chamou a atenção o desenho de um arcoíris com cores "vivas", demonstrando, um estado de entusiasmo, alívio e satisfação na realização das propostas, podendo-se inferir que a criança/paciente está aceitando bem sua condição de hospitalização.

As histórias reportavamas crianças hospitalizadas à família, à escola e aos amigos que ficaram "lá fora". Eram recordações que possibilitavam a redação e reprodução de histórias cheias de emoções, medos, angústias, mas também de alegria e resgate do convívio familiar e social.

Os contos com sua linguagem simbólica auxiliam as crianças a lidar de maneira mais positiva com as angústias e insegurança emocional diante da condição de hospitalização, propiciando, de forma lúdica, a resolução dos medos, restaurando-se a confiança e o bem estar (SOUZA; BERNARDINO, 2011), além de promover o processo da aprendizagem.

Aspectos fundamentais foram observados quanto ao nível de aprendizagem, como por exemplo, identificar que uma história deve ter um início, meio e fim, demonstrados pela expressão inicial Era uma vez... e finalizado com um dia morreu, como pode ser observado na reprodução abaixo:

Era uma vez, uma menina que vivia na sua casa, não saía para brincar. Um dia triste bateu uma pessoa na porta e chamou-a para brincar, e como muito que não saía da casa, saiu para brincar, mas tinha uma doença rara e todo dia sai para brincar. Um dia morreu e um menino e fim.

Tal redação demonstra que a criança recorre a conteúdos já adquiridos na escola regular e aos encontros anteriores, estando presente o medo, a angústia, a solidão e a falta de compreensão 
sobre sua enfermidade, levantando a questão da terminalidade. Nesse sentido, os contos auxiliam a criança "no desenvolvimento de seu intelecto e tornam claras suas emoções" (MEIRELLES, 1997)

Ressalta-se, entretanto, que o intuito da Contação de Histórias, não era o de diagnosticar o nível de alfabetização da criança, mas observar o que a história poderia revelar sobre aquele momento vivenciado, aproximando-a de um ambiente lúdico de aprendizagem.

Pode-se observar ainda, um senso crítico nas narrativas, bem como noções de ética e moral. Eram solícitas em dividir os materiais utilizados na intervenção, tanto no manuseio de fantoches quanto na divisão dos lápis de cor utilizados em algumas atividades. Por outro lado, observou-se também questões relacionadas à indisciplina, tal como ocorre nas escolas regulares.

É possível observar que os contos de fadas, além da diversão, são importantes para a formação da criança e para sua aprendizagem, atuando, de acordo com Villardi (1997), no desenvolvimento da inteligência, criatividade e socialização, sendo ainda um estímulo ao prazer da leitura. Nesse sentido, a Contação de Histórias poderá ser a motivação necessária para que a criança adquira o gosto pela leitura, abrindo possibilidades infinitas de aprendizagem e compreensão de seu lugar no mundo.

\section{3 - Importância da proposta para os pais ou responsáveis}

A entrevista com os pais ou responsáveis teve como objetivo verificar a importância do desenvolvimento das atividades de Contação de Histórias para seu filho no momento de internação, sendo que apenas quatro pais aceitaram participar.

Todos os pais participantes ressaltaram a importância da proposta, revelando que os filhos ficaram mais tranquilos, mesmo neste momento de inquietação e tensão, em razão dos procedimentos cirúrgicos e da hospitalização, conforme ilustrado abaixo:

Minha filha estava inquieta, e tendo alguma atividade para ela realizar ficará mais tranquila e até mesmo para nós acompanhantes (PAI 1).

O momento de espera para a cirurgia nos deixa bem tensos, e este momento [lúdico] está nos deixando mais calmas (MÃE 2).

Minha filha estava chateada lá na cama e agora está com sorriso no rosto (MÃE 3).

Os dados deste estudo corroboram com os achados de Souza e Bernardino (2011, p. 247) os quais afirmam que "O desenvolvimento infantil se dá num processo criado pela própria criança a partir das interações que vivencia, sendo assim, a literatura infantil em especial a Contação de Histórias na educação infantil e ensino fundamental, como atividade interativa e pedagógica mediada pelo educador contribui para este desenvolvimento."

De acordo com as autoras, a Contação de Histórias, consiste e uma boa ferramenta para o professor da pedagogia hospitalar, uma vez que a criança na condição de hospitalização está privada de seu ambiente familiar, escolar e social, com poucas possibilidades de expressar sua ludicidade, própria da fase infantil. Nesse sentido, os contos e histórias, durante o período de internação, permitem o desenvolvimento de atividades próximas de seu cotidiano, favorecendo a aprendizagem e a minimização do sofrimento físico e psíquico, além de permitir relações mais saudáveis com os profissionais da saúde.

E, a presença dos pais apoiando os filhos, seja neste momento de fragilidade ou nas atividades regulares de aprendizagem ou lúdicas é extremamente importante, promovendo-lhes a confiança necessária para seu pleno desenvolvimento. 


\section{Considerações Finais}

Os resultados apontaram que a Pedagogia Hospitalar e, especificamente, a estratégia de Contação de Histórias pode trazer contribuições à instituição hospitalar, as crianças hospitalizadas e a seus pais ou responsáveis.

Com as crianças pode contribuir favorecendo formas de enfrentamento mais positivas diante do processo cirúrgico e hospitalização, bem como promover uma aproximação com o cotidiano escolar e a aprendizagem.

Para a instituição hospitalar e, especialmente, o setor da pediatria, favorece uma relação mais harmoniosa entre a equipe de saúde, paciente e pais ou responsáveis, reduzindo as ansiedades e tensões provocadas pelo adoecimento e hospitalização.

No entanto, ressalta-se a necessidade de uma prática mais efetiva, no sentido de implantar Classes Hospitalares, visando assistir aos pacientes infantis quanto a sua escolaridade, não se restringindo apenas a projetos esporádicos, muitas vezes, oriundos de estágios curriculares supervisionados em Pedagogia ou Psicologia. Atualmente, não existe, neste Hospital, o atendimento em Classe Hospitalar sistematizado. A demanda para tal existe, especialmente, na Unidade Pediátrica Oncológica, em que as crianças passam longos períodos de internação.

Este estudo não teve a pretensão de generalizar os dados para toda e qualquer situação de crianças/ alunos hospitalizados, todavia, infere-se que tais estudos poderiam ser aprofundados por meio de pesquisas que correlacionem as práticas pedagógicas desenvolvidas no contexto hospitalar com o desempenho escolar do aluno ao regressar ao ensino regular.

\section{Referências}

ASSIS, W. Classe hospitalar: um olhar pedagógico singular. São Paulo: Phorte, 2009.
BARDIN, L. Análise de conteúdo. Lisboa: Ed. 70, 2009.

BETTELHEIM, B. A psicanálise dos contos de fadas. Rio de Janeiro: Paz e Terra, 2008.

BONOTTO, M. E. K. Chapeuzinho amarelo: um novo sentido para uma velha história. Em Questão, Porto Alegre, v.9,n.1,p.55-68,2003.Disponívelem: $<$ https://www.lume. ufrgs.br/bitstream/handle/10183/129333/000399604. pdf? sequence $=1 \&$ locale-attribute $=$ es $>$ Acesso em: 31 mar. 2018.

BRASIL. Lei $n^{\circ} 11.104$, de 21 de março de 2005. Dispõe sobre a obrigatoriedade de instalação de brinquedotecas nas unidades de saúde que ofereçam atendimento pediátrico em regime de internação. Disponível em: $<$ http://www.planalto.gov.br/ccivil_03/_ato20042006/2005/lei/111104.htm>. Acesso em: 31 mar. 2018.

BRASIL. Ministério da Educação. Resolução $n^{\circ} 02$ de 11 de setembro de 2001. Institui as Diretrizes Nacional para a Educação Especial na Educação Básica. Disponível em: <portal.mec.gov.br/cne/arquivos/pdf/CEB0201. pdf $>$. Acesso em: 22 nov. 2016.

BRASIL. Ministério da Educação. Resolução $n^{\circ} 1$ de 15 de maio de 2006. Institui as Diretrizes Curriculares Nacional para o Curso de Graduação em Pedagogia, licenciatura. Disponível em: <http://portal.mec.gov.br/ cne/arquivos/pdf/rcp01_06.pdf $>$. Acesso em: 31 mar. 2018.

BRASIL. Ministério da Educação. Secretaria de Educação Especial. Classe hospitalar e atendimento pedagógico domiciliar: estratégias e orientações. Brasília, 2002. Disponível em: <http://portal.mec.gov. br/seesp/arquivos/pdf/livro9.pdf $>$. Acesso em: 31 mar. 2018.

CASTRO, D. P. et al. Brincar como instrumento terapêutico. Pediatria, São Paulo, v. 32, n. 4, p. 246-254, 2010. Disponível em: <https://www.researchgate.net/ publication/280947178_Brincar_como_instrumento_ terapeutico $>$. Acesso em: 31 mar. 2018.

CASTRO, M. Z. Educação e saúde de mãos dadas para humanizar: desafios e perspectivas. In: MATOS, E. L. M. (Org.). Escolarização hospitalar. Petrópolis: Vozes, 2009. p. 47-57.

CONSELHO NACIONAL DOS DIREITOS DA CRIANÇA E DO ADOLESCENTE. Resolução $n^{\circ}$ 41 de 13 outubro de 1995. Direitos da Criança e do Adolescente Hospitalizado. Disponível em: <http:// www.mpdft.mp.br/portal/pdf/unidades/promotorias/ pdij/Legislacao\%20e\%20Jurisprudencia/Res_41 95 Conanda.pdf $>$. Acesso em: 31 mar. 2018. 
ESTEVES, C. R. Pedagogia hospitalar: um breve histórico. Disponível em: $<$ https://pedagogiaaopedaletra. com/wp-content/uploads/2013/06/HIST\%C3\%93RICODA-PEDAGOGIA-HOSPITALAR.pdf $>$. Acesso em: 31 mar. 2018.

MATOS, E. L. M. Escolarização hospitalar. Petrópolis: Vozes, 2009.

MATOS, E. L. M.; MUGIATTI, M. M. T. F. Pedagogia hospitalar. Curitiba: Champagnat, 2006.

MEIRELLES, C. Problemas da literatura infantil. São Paulo: Summus, 1997.

SÃO PAULO (Estado). Lei 10.685, de 30 de novembro de 2000. Dispõe sobre o acompanhamento educacional da criança e do adolescente internados para tratamento de saúde. Disponível em: <https://www.al.sp.gov.br/ repositorio/legislacao/lei/2000/lei-10685-30.11.2000. html >. Acesso em: 31 mar. 2018.
SISTO, C. Textos e pretextos sobre a arte de contar histórias. Chapecó: Argos, 2001.

SOUZA, L. O.; BERNARDINO, A. D. A contação de histórias como estratégia na educação infantil e ensino fundamental. Educere et Educare, Cascavel, v. 6, n. 12 p. 235-249, jul. /dez. 2011.

VIGOTSKI, L. S. La imaginación y el arte en la infancia. Madrid: Akal, 2003.

VILLARDI, R. Ensinando a gostar de ler: formando leitores para a vida inteira. Rio de Janeiro: Qualitymark, 1997.

WALLON, H. Psicologia e educação da infância. Lisboa: Estampa, 1975. 
